\title{
Editorial: The 2019 François Naftali Frenkiel Award for Fluid Mechanics
}

The recipients of the 36th François Naftali Frenkiel Award for Fluid Mechanics are Thomasina Ball and Jerome Neufeld for their paper "Static and dynamic fluid-driven fracturing of adhered elastica" which was published in Phys. Rev. Fluids 3, 074101 (2018). They were presented with this award on November 26, 2019 at the annual meeting of the APS Division of Fluid Dynamics in Seattle, Washington. Both authors received a check for $\$ 500$ plus a scroll acknowledging the award. The Frenkiel Award citation reads: "For insightful experiments combined with theory that unravel distinct dynamical regimes observed in the spreading of viscous fluids beneath elastic sheets."

The purpose of this Award, which is named after Dr. F. N. Frenkiel, founder and longtime editor of Physics of Fluids, from which Physical Review Fluids evolved, is to recognize significant contributions in fluid mechanics by young investigators. The Award is sponsored by the Division of Fluid Dynamics of the APS and beginning with the 2017 award has been given annually to a young author of a paper that has been published in Physical Review Fluids, during the calendar year preceding the presentation. "Young" will normally be defined as being under 40 years of age. More than one author may be involved, and one author may be a thesis advisor sharing the Award if he/she is also under 40. The winner of this Award is selected by a committee appointed by the Chair of the Division of Fluid Dynamics of the APS.

François Naftali Frenkiel was born in Warsaw, Poland on September 19, 1910, and received his Ph.D. in Physics from the University of Lille in France, where he studied under the direction of Kampé de Fériet. He came to the U.S. in 1947 and was associated successively with Cornell University, the U.S. Naval Ordnance Laboratory, the Johns Hopkins University Applied Physics Laboratory, and, from 1960 until his retirement, with the David W. Taylor Naval Ship Research and Development Center. In addition to being the founder and longtime editor of Physics of Fluids, he served on a large number of national and international committees, including the Division of Fluid Dynamics of the American Physical Society, of which he was the chairman and secretary on numerous occasions. $\mathrm{He}$ published extensively in the field of turbulent flows and pioneered the application of high-speed digital computing methods to the measurement of turbulence and the mathematical modeling of urban pollution. Dr. Frenkiel retired in 1981 and passed away on July 9, 1986, in Washington, DC. 


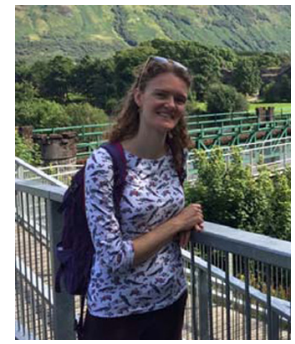

Thomasina Ball received her Ph.D. in Earth Sciences at the University of Cambridge (Cambridge, UK) in 2019 and is currently a postdoctoral researcher at the University of British Columbia, Canada. Her research interests cover non-Newtonian fluid dynamics and fluid-structure interactions with applications to geophysical phenomena.

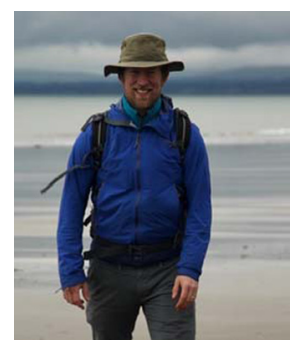

Jerome Neufeld is a Reader in Earth and Planetary Fluid Dynamics jointly appointed to the BP Institute, the Department of Earth Sciences, and the Department of Applied Mathematics and Theoretical Physics at the University of Cambridge. The research in his group focuses on using mathematical models and laboratory experiments to understand the fluid dynamical behavior of the Earth and other planetary bodies. Current research interests include the consequences of subglacial hydrology on supraglacial lake drainage and the tidal modulation of ice streams, the solidification of magma oceans and the early generation of magnetic fields on planetary bodies, the erosive dynamics of idealized river systems, the emplacement and solidification of magmatic flows, viscous tectonic mountain building, and the general fluid dynamics of geological carbon storage. Dr. Neufeld has a Ph.D. in geophysics from Yale University, a B.A.Sc. in Engineering Science (physics) from the University of Toronto, and is an Official Fellow in physics at St. Catharine's College, Cambridge.

John Kim

Gary Leal

Editors

Published 28 January 2020

DOI: 10.1103/PhysRevFluids.5.010001 